\title{
A COMUNICAÇÃO EM FAMÍLIAS COM FILHOS ADOLESCENTES ${ }^{1}$
}

\author{
Adriana Wagner* \\ Denise Falcke \\ Luiza Maria Braga de Oliveira Silveira \\ Clarisse Pereira Mosmann ${ }^{\infty}$
}

\begin{abstract}
RESUMO. A adolescência é considerada um período no qual ocorre um incremento nos confrontos entre pais e filhos. Objetivou-se, então, conhecer como os adolescentes avaliam a comunicação que estabelecem na família. Foram investigados 295 jovens com idades entre 11 e 16 anos. Aplicou-se um questionário que avaliava a comunicação do adolescente com os membros da sua família. Os resultados apontam que a mãe é a pessoa mais procurada para conversar (49,8\%), seguida pelo irmão mais velho $(17,6 \%)$ e depois pelo pai $(12,2 \%)$ e pelo irmão mais novo $(2,4 \%)$. Os dados refletem uma estrutura familiar na qual a mãe aparece como a principal responsável pelo cuidado e mediação das relações familiares, enquanto o pai ocupa um lugar mais periférico. Os adolescentes também informaram ter um bom nível de comunicação em casa, sendo que $96 \%$ consideram a comunicação familiar como algo muito importante.
\end{abstract}

Palavras-chaves: comunicação, família, adolescência.

\section{THE COMMUNICATION IN THE FAMILIES WITH ADOLESCENTS CHILD}

\begin{abstract}
Adolescence is regarded as a period in which difficulties in family communication and an increase in confrontations between parents and children take place. We set out to understand how adolescents evaluate the frequency and quality of the communication they establish with their parents and siblings. 295 youngsters were investigated, 141 males and 154 females, ages ranging between 11 and 16 years old. A questionnaire was administered, with simple choice closed questions which aimed to evaluate the communication of the adolescent with differents members of the family. Results point at the mother as the most sought out person for conversation $(49,8 \%)$, followed by the eldest sibling $(17,6 \%)$ and then the father $(12,2 \%)$ and the youngest sibling $(2,4 \%)$. Data reflect a family structure in which the mother appears as the main responsible for care and mediation of the familiar relationships, whereas the father occupies a more peripheral place. The adolescents report a good level of communication at home and $96 \%$ of them evaluate family communication as very important.
\end{abstract}

Key words: communication, family, adolescence.

A adolescência é uma fase de emoções intensas, na qual o sujeito está em busca da consolidação da sua própria identidade. Como uma das primeiras manifestações deste processo, ocorre o afastamento da família de origem e um maior envolvimento com o grupo de iguais. Esse afastamento das figuras parentais, em muitos momentos, pode tomar a forma de rebeldia, mesmo quando não existem motivos aparentes para isso. Roger Moreira, compositor e vocalista do conjunto de rock paulista Ultraje a Rigor, descreve esse fenômeno como a reclamação de um Rebelde Sem Causa:

\begin{abstract}
Meus dois pais me compreendem totalmente (como é que cê se sente, desabafa aqui com a gente). Meus dois pais me dão apoio moral (não dá pra ser legal, só pode ficar mal). (...) Não vai dar, assim não vai dar, como é que eu vou crescer sem ter com quem me revoltar. Não vai dar, assim não vai dar, pra eu amadurecer sem ter com quem me rebelar.
\end{abstract}

1 Apoio Financeiro: CNPq, CAPES e FAPERGS.

* Doutora, Professora Adjunta do curso de Pós-Graduação da PUCRS.

Endereço para correspondência: Rua Vicente da Fontoura, 2059/504, 90640-003, Porto Alegre - RS. E-mail: wagner@pucrs.br

\# Psicóloga, Terapeuta de casais e famílias, doutoranda em Psicologia, PUCRS, bolsista CAPES.

II Psicóloga, mestre em Psicologia pela PUCRS.

æ Estudante de Psicologia, Bolsista de Iniciação Científica CNPq. 
Estes versos trazem a ilustração de um panorama de como se estabelecem as relações em uma família com filhos nessa faixa etária. Pode-se observar que as características próprias da fase adolescente, que são, muitas vezes, expressas através de comportamentos e desejos ambivalentes, definem o tom de como os jovens vivenciam e relatam as suas experiências familiares. Neste contexto, a comunicação entre os membros da família se torna peça fundamental para potencializar e auxiliar o estabelecimento de relações mais satisfatórias e saudáveis. Tendo-se em vista a importância da comunicação familiar nessa fase, cabe investigar como ela ocorre entre os membros desses núcleos. Com quem o filho adolescente mais conversa? Quem ele pensa que o entende melhor? Essas são algumas questões que permeiam este trabalho.

A literatura está repleta de registros indicando que a comunicação em uma família com filhos adolescentes se caracteriza por um acréscimo nos confrontos entre pais e filhos. Este fenômeno ocorre em função de que passa a haver um maior questionamento do filho adolescente com relação às regras, valores e crenças familiares (Blos, 1996; Osório, 1992; Aberastury \& Knobel, 1990). Muitas vezes, os pais se surpreendem com as atitudes dos filhos, que ficam mais instáveis, irritados e questionadores atitudes essas que para os próprios adolescentes podem representar uma forma de diferenciação das figuras parentais e busca de sua própria identidade. Nesse processo, é comum os jovens manifestarem ataques de raiva, isolarem-se em quartos fechados, buscarem apoio nos avós ou começarem a apresentar comportamentos sexuais desafiadores ou de risco (Carmona, 2000; Carter \& McGoldrick, 1995).

Em vista das novas demandas que ocorrem no relacionamento familiar na fase adolescente, faz-se necessário que haja um aumento na flexibilidade das fronteiras e equilíbrio na autoridade dos pais, no intento de manter a harmonia familiar. Famílias com fronteiras mais flexíveis permitem que o adolescente possa transitar e experimentar-se livremente em diferentes territórios, aproximando-se quando sente-se inseguro e afastando-se para experienciar sua independência (Cerveny \& Berthoud, 1997; Richter, 1990). Nesse cenário, exigem-se esforços de todos os membros na busca de novos padrões de convivência familiar, adaptados a este momento específico do ciclo vital da família. Como fica, então, o relacionamento do adolescente com cada membro de sua família?

No que diz respeito ao papel da mãe, pesquisas indicam que, apesar de a mulher ter ingressado no mercado de trabalho, aumentado seu número de atividades fora do lar e seu poder econômico, o dever doméstico e, principalmente, o cuidado e educação dos filhos ainda são funções desempenhadas principalmente por ela (Grzybowsky, 2000; Data Folha, 1998). Desde esta perspectiva, pode-se verificar que, independentemente das transformações que a família vem sofrendo, as funções e papéis tradicionais, baseados nos estereótipos de gênero, permanecem vinculados à mulher, cabendo principalmente a ela a função de cuidadora do lar e dos filhos (Wagner, Halpern \& Bornholdt, 1999).

Neste caso, pode-se dizer que, ao invés de ter ocorrido uma mudança das funções que historicamente têm sido desempenhadas pela mulher, a realidade atual indica um acúmulo de novas funções ao papel feminino na família (Falcke, 1998). Em vista do aumento da complexidade das atribuições da mulher no núcleo familiar, é possível supor que cabe principalmente à mãe o papel de conversar e estar atenta às necessidades e aos interesses dos filhos. Pergunta-se então: Será a mãe a pessoa que os filhos mais procuram para conversar?

Uma pesquisa realizada por Pick e Palos (1995) nesta perspectiva constatou que existe uma diferença significativa na maneira pela qual a mãe e o pai se comunicam com seus filhos. Os resultados mostraram que, tanto do ponto de vista da mãe quanto dos filhos, a mãe é quem se comunica- melhor com os filhos adolescentes, independentemente do sexo destes.

Frente a estes dados e considerando o acúmulo das novas funções maternas, perguntamos: o que pode ter mudado com relação às funções paternas? Que papel o pai está exercendo no núcleo familiar?

A pluralidade dos modelos de estrutura e configuração familiar que coexistem na atualidade foi expressa por Horta (1998) ao revisar a literatura sobre as transformações do papel do pai. Ao mesmo tempo em que alguns estudiosos afirmam terem os pais assumido com maior frequiência e qualidade os cuidados de filhos e filhas, outros apontam que estas mudanças são muito pequenas e não afetam, em essência, a clássica divisão entre o que é feminino e o que é masculino no desempenho dos papeis familiares. Corroborando essa idéia, Wagner e cols. (1999) comprovaram que ainda permanece, de forma mais freqüente, relacionada à figura masculina e à função paterna a atribuição tradicionalmente conferida ao pai, de prover ao sustento econômico da família.

Dessa forma, parece que são iniciais as mudanças que vêm ocorrendo quanto às funções parentais na família, permanecendo ainda estabelecidas algumas atribuições vinculadas às questões de gênero, como por exemplo, da mãe, de cuidar dos filhos e do pai, de prover o sustento familiar.

Ampliando a visão dos relacionamentos que ocorrem no núcleo familiar definido neste contexto, inquieta-nos, também, conhecer como tem se estabelecido a relação entre os irmãos na fase da adolescência.

Neste sentido, sabe-se a partir do senso comum que, nas interações fraternas, oscilam sentimentos de afeição, solidariedade e rivalidade, hostilidade. As experiências compartilhadas no relacionamento 
fraterno são consideradas as primeiras e mais intensas entre iguais, pois, diferentemente do subsistema parental, espera-se que as relações se estabeleçam no mesmo nível hierárquico. Nesse grupo de iguais, portanto, os irmãos aprendem a dividir o espaço e as regras familiares, que são a base de suas futuras relações (Perez, 1998; Silveira, 2001).

Sabe-se, entretanto, que o relacionamento entre irmãos possui características diferenciadas de acordo com a fase do ciclo evolutivo vital emque a família se encontra. $\mathrm{Na}$ adolescência, a partir do momento em que ocorre a aceitação das transformações inerentes a essa etapa, a relação pode assumir características mais positivas e menos conflitivas (Cicirelli, 1995). Observa-se então que os irmãos mais novos procuram os irmãos mais velhos para discutir com eles assuntos sobre os quais se sentem desconfortáveis para conversar com seus pais (Bank \& Kahn, 1997).

Pensando-se nessas inter-relações que se estabelecem entre os membros da família e na definição dos papéis de pai, mãe e irmão; verifica-se que na adolescência as transformações ocorrem, não somente, num nível intrapsíquico, mas também relacional. Nesse sentido, a demanda do adolescente por maior independência e participação nas decisões familiares exige uma reorganização nos padrões de funcionamento familiar. Esses serão favorecedores da confiança, aceitação e afeto entre pais e filhos, quando associados a uma comunicação clara e direta. Nesta forma de comunicarem-se, os limites se apresentam nítidos e permeáveis para cada um dos membros do sistema familiar (Wagner, Ferreira \& Rodrigues, 1998).

Baseado nestes pressupostos e buscando conhecer melhor como se dá a comunicação e a relação entre os diferentes membros da família, esse trabalho objetiva conhecer como os adolescentes avaliam a freqüência e a qualidade da comunicação que se estabelece com seus pais e irmãos

\section{MÉTODO}

\section{Amostra}

A amostra constituiu-se por 295 adolescentes de nível socioeconômico-cultural médio, todos de famílias intactas, com idades variando entre 11 e 16 anos, sendo 141 do sexo masculino e 154 do sexo feminino. Todos os sujeitos freqüentavam a $6^{\mathrm{a}}, 7^{\mathrm{a}}$ e $8^{\mathrm{a}}$ séries do ensino fundamental de duas escolas particulares de Porto Alegre. As famílias tinham em média uma prole de 2,33 filhos, distribuídos da seguinte maneira:

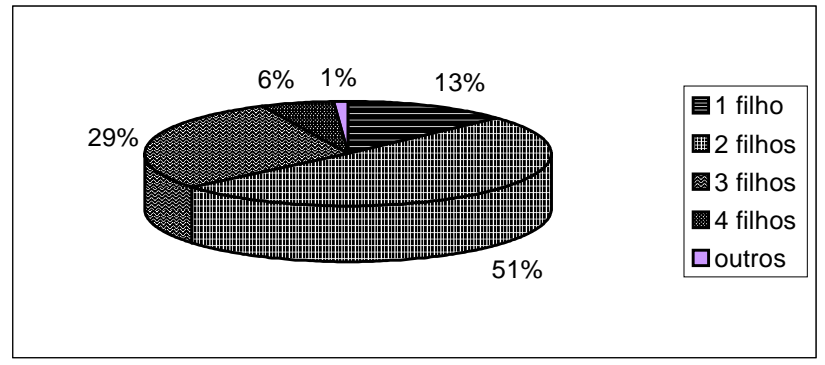

Gráfico 1. Número de filhos

Quanto ao lugar do sujeito na prole verificou-se que $43,1 \%$ eram primogênitos, $38,3 \%$ o segundo filho, $14,9 \%$ o terceiro filho e $3,1 \%$, o quarto filho.

\section{Instrumento e procedimentos}

O instrumento utilizado foi um questionário autoaplicável, contendo perguntas fechadas de escolha simples que avaliavam como se dava a comunicação do adolescente com a sua família em geral e com os diferentes membros, bem como a importância que ele atribuía à comunicação familiar.

Para a coleta dos dados foi solicitada a autorização da direção das escolas. Cada escola que autorizou a coleta dos dados indicou as turmas às quais se poderiam aplicar os questionários ,conforme a disponibilidade de horários. A partir disso, os questionários foram aplicados coletivamente, em sala de aula, com duração aproximada de 20 minutos. Solicitou-se aos alunos que não deixassem em branco nenhuma questão e enfatizou-se o anonimato dos questionários.

\section{RESULTADOS}

Inicialmente, apresenta-se uma análise descritiva dos resultados, de como se estabelece a comunicação do sujeito com cada um dos membros de sua família (pai, mãe e irmãos(as)), a fim de conhecer a frequiência das conversas, o grau de entendimento e o nível de coerência que os adolescentes observam em cada personagem a partir do critério congruência entre discurso e atitudes.

Posteriormente, fez-se uma análise bivariada a partir do teste do quiquadrado - considerando $\mathrm{P} \leq 0,05$ a fim de avaliar o grau de associação entre os diferentes personagens da família (pai- mãeirmãos(as) mais velhos(as) e mais novos(as)) e o papel que cada um desempenha junto ao adolescente no que se refere a comunicação familiar.

\section{O pai}

Buscando avaliar a freqüência das conversas que os adolescentes têm com o pai, encontraram-se 
resultados polarizados. Na amostra de 295 sujeitos, $48,9 \%$ referem que conversam poисо com a figura paterna, enquanto $40,7 \%$ revelam uma prática de ter muitas conversas com o pai.

Nesses diálogos, a maior parte dos sujeitos $(56,3 \%)$ diz conseguir de forma freqüente chegar a algum acordo com ele, apontando para uma relação de compreensão e troca entre pai e filho(a). Já 39,8\% dos sujeitos declaram ter um entendimento pleno com seu pai, sentindo-se sempre compreendido por ele. Apenas 3,9\% dos jovens referem nunca haver possibilidade de fazer acordos com o pai.

Avaliando a coerência do pai entre aquilo que ele diz e o que pratica, $53,7 \%$ dos adolescentes afirmam que o pai é muito coerente e $39,9 \%$ reconhecem alguma coerência entre o discurso e a conduta do seu pai. Este dado indica que a figura paterna nestas famílias mantém um papel de credibilidade frente aos filhos.

\section{A mãe}

A freqüência do diálogo com a figura materna é bastante alta. A grande maioria dos adolescentes (75\%) afirma que conversa muito com a sua mãe e apenas $2,1 \%$ dos sujeitos referem não conversar nada. Este dado pode estar revelando uma maior proximidade desta personagem assim como melhores possibilidades de compreensão e entendimento. Avaliando-se de forma específica esta variável, verifica-se que $51,9 \%$ consideram-se sempre entendidos pela mãe e $45,4 \%$ manifestam que freqüentemente conseguem chegar a um acordo com ela.

Provavelmente estes resultados se explicam pelo alto grau de coerência que os jovens observam entre $o$ discurso e as atitudes de sua mãe. Na amostra, 64,9\% dos sujeitos avaliam a sua mãe como muito coerente, enquanto apenas 1,7\% declarou que ela nunca é coerente.

\section{Comparação entre pai e mãe}

$\mathrm{Na}$ análise das variáveis estudadas, observou-se uma diferença significativa $(\mathrm{p}<0,01)$ na forma como os adolescentes avaliam a relação que estabelecem com o pai e com a mãe.

Considerando-se a freqüência de conversas, verifica-se que $75 \%$ dos sujeitos referem dialogar muito com a mãe, enquanto , de forma contrária, $40,7 \%$ indicam conversar pouco ou nada com o pai, o que denota uma ampla discrepância entre as figuras parentais $\left(\chi^{2}=27,39 ;\right.$ g.l. $\left.=4 ; \mathrm{p} \angle 0,01\right)$.

Da mesma forma, a mãe, significativamente mais do que o pai, aparece como o membro que compreende o adolescente, sendo mais capaz de estabelecer trocas e chegar a acordos $\left(\chi^{2}=33,08\right.$; g.l. $=4 ; \mathrm{p} \angle 0,01)$.

Tanto a coerência paterna como a materna, entre discurso e atitudes, foram valorizadas pelos adolescentes. Do total, $41,3 \%$ dos sujeitos referem que tanto o pai como a mãe são muito coerentes naquilo que dizem e praticam. Todavia, a análise estatística aponta uma diferença significativa a favor da mãe, isto é, a mãe é vista por eles como mais coerente que o pai $\left(\chi^{2}=21,96 ;\right.$ g.l $\left.=4 ; \mathrm{p} \angle 0,01\right)$.

\section{Irmãos mais velhos}

Dos adolescentes que possuem irmãos mais velhos, a maioria $(87,8 \%)$ refere manter diálogos com eles. Um total de $58,7 \%$ referiu conversar com muita freqüência e $29,1 \%$ disseram falar moderadamente com os irmãos mais velhos. Somente uma minoria $(12,2 \%)$ refere não conversar com os irmãos.

Os sujeitos percebem um alto grau de entendimento no relacionamento fraterno. Dentre os jovens deste estudo, $87,8 \%$ sentem-se freqüentemente entendidos, acreditando que podem contar com a compreensão dos irmãos.

Considerando-se a congruência entre o discurso e a prática dos irmãos mais velhos, também a maioria dos sujeitos $(87 \%)$ considera seus irmãos coerentes. Percebe-se, então, que os irmãos mais velhos parecem desempenhar um papel bastante importante junto aos adolescentes participantes deste estudo.

Nota-se que, apesar de baixas, são muito semelhantes as porcentagens que indicam grande dificuldade de comunicação entre os irmãos, apontando para quase nenhum tipo de interação $(12,2 \%)$, descrédito pela pouca coerência percebida no irmão (13\%) e inexistência de entendimento $(12,2 \%)$.

\section{Irmãos mais novos}

O relacionamento com os irmãos mais novos não foi muito valorizado pelos adolescentes. Dentre as alternativas apresentadas, 46,7\% referiram conversar pouco com eles e $20,4 \%$ foram mais enfáticos indicando que não conversam nada.

Um dos motivos para esta falta de diálogo pode ser o fato de os adolescentes não se sentirem compreendidos pelos irmãos mais jovens, ou também por haver muita diferença de idade entre os irmãos, estando os mais novos ainda na primeira infância. A maioria dos sujeitos assinala sentir-se entendida por seus irmãos mais novos somente às vezes $(55,8 \%)$ ou 
nunca $(25,6 \%)$. Da mesma forma, os jovens avaliam que seus irmãos mais novos às vezes $(63,1 \%)$ ou nunca $(24,6 \%)$ são coerentes.

\section{Comparação entre irmãos novos e irmãos mais velhos}

Verificando-se quanto os adolescentes conversam com seus irmãos, constatou-se uma tendência $\left(\chi^{2}=8,40 ;\right.$ g.l $\left.=4 ; p=0,08\right)$ de eles conversarem mais freqüentemente com os irmãos mais velhos, provavelmente devida a uma maior possibilidade de entendimento com estes do que com os mais novos $\left(\chi^{2}=20,59 ; \quad\right.$ g.l. $\left.=4 ; \quad \mathrm{p} \angle 0,01\right)$. Os dados refletem também que os adolescentes consideram os irmãos mais velhos significativamente mais coerentes do que os irmãos mais novos $\left(\chi^{2}=13,89 ;\right.$ g.l $\left.=4 ; p=0,008\right)$.

\section{Com quem o adolescente mais conversa?}

Após essa descrição inicial onde os adolescentes caracterizaram sua comunicação com cada um dos membros da família, questionou-se sobre com qual dessas pessoas eles mais gostam de conversar. As respostas se distribuíram da seguinte forma:

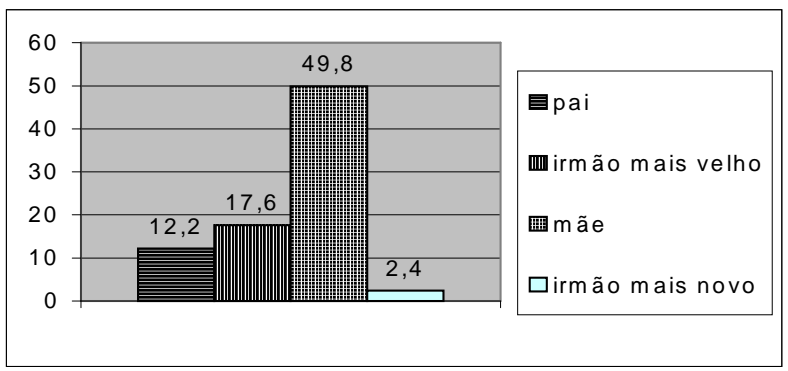

Gráfico 2. Com quem mais gosta de conversar

Observa-se que a mãe foi citada por quase a metade dos adolescentes da amostra $(49,8 \%)$ como a pessoa com quem eles mais gostam de conversar. $\mathrm{Na}$ sequiência, os adolescentes assinalam o irmão mais velho $(17,6 \%)$, seguido pelo pai $(12,2 \%)$ e, finalmente, o irmão mais novo $(2,4 \%)$.

Considerando-se separadamente as respostas de meninos e meninas a esta questão, verificou-se que existe diferença significativa $(\mathrm{p}=0,000)$ quanto à escolha das figuras parentais. Apesar de ambos referirem gostar de conversar mais com a mãe (57\% das meninas e $44,4 \%$ dos meninos), o pai é citado preponderantemente pelos meninos $(21,5 \%)$, em comparação com as meninas (somente $4,6 \%$ ).

Já ao ser solicitados que considerassem a importância da comunicação nas famílias em geral, os adolescentes a consideraram:

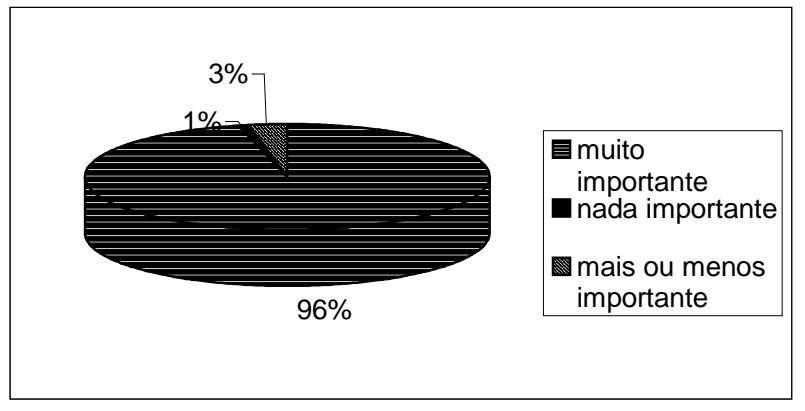

Gráfico 3. Importância da comunicação

Pode-se concluir que a grande maioria dos sujeitos consideram a comunicação nas famílias um aspecto de muita importância.

\section{DISCUSSÃO DOS RESULTADOS}

A partir dos resultados encontrados nesta pesquisa e dos postulados da literatura sobre o tema, podemos refletir sobre como o adolescente percebe a comunicação em seus núcleos familiares, avaliando a importância que ele atribui a esse processo e como ele se comunica com os diferentes membros de sua família.

Partindo-se da forma como os adolescentes avaliam a comunicação que mantêm com cada um dos membros de sua família, observou-se que existe uma certa hierarquia que define qual a pessoa escolhida pelos adolescentes para conversar. Confirmando os dados da literatura (Pick \& Palos, 1995; Carmona, 2000), a mãe é citada, pela maioria dos adolescentes, como a pessoa da família com quem os adolescentes mais conversam, sendo considerada uma pessoa muito coerente e com grande capacidade de entendimento.

Esses dados parecem corroborar a tradicional função da mãe como responsável pelo cuidado e mediação das relações familiares. Cabe a ela, normalmente, a função de cuidadora do lar e dos filhos, o que exige que converse e permaneça atenta às necessidades e interesses de todos os membros da família (Wagner, Halpern, \& Bornholdt, 1999).

Em oposição ao que foi observado sobre o relacionamento com a figura materna, os adolescentes referem que conversam pouco com o pai, o que confirma achados de pesquisas recentes (Horta 1999; Wagner, 1999). Observa-se que, apesar e a figura paterna estar desempenhando suas funções com maior qualidade e freqüência atualmente, o pai ainda ocupa, de forma genérica, um lugar periférico na vida do adolescente no que se refere às questões mais pessoais e de contato íntimo. Este fato está, provavelmente, associado ao dado de que a maioria dos adolescentes consideraram o pai como alguém que nem sempre os entende (56,3\%). Esta característica do entendimento entre pai e filhos adolescentes pode estar relacionada ao papel 
tradicionalmente atribuído à figura paterna, de disciplinador e provedor do sustento familiar em detrimento de uma maior exigência de envolvimento com questões afetivas. Entretanto, apesar de os jovens reconhecerem que não conversam tão freqüentemente com seu pai e existir dificuldade de entendimento entre eles, o pai é considerado muito coerente em seu discurso e atitudes $(53,7 \%)$. Nesse caso, pode-se verificar que o pai, ainda que não seja um interlocutor freqüente do adolescente, é uma figura avaliada de forma positiva.

A partir do tipo de relação que se estabelece entre o adolescente e seu pai, o irmão mais velho parece entrar na dinâmica familiar como quem supre a baixa freqüência de diálogo com a figura paterna. Um total de 17,6\% dos sujeitos refere que o irmão mais velho é a pessoa da família com quem eles ais gostam de conversar, enquanto12,2\% dizem preferir conversar com o pai.

Neste caso, os irmãos mais velhos, frequientemente, assumem o papel de ensinar e auxiliar no manejo de situações difíceis, pelo fato de já terem vivenciado anteriormente tais situações. Ainda que na adolescência haja uma tendência de aumento dos conflitos fraternos, também cria-se uma possibilidade de maior troca entre os irmãos. Resultados de outras pesquisas (Ciccirelli, 1995) também evidenciam nesta fase uma maior disponibilidade e tempo de diálogo entre os irmãos. Sendo assim, parece que o subsistema fraterno se revela como um espaço potencial de saúde e entendimento familiar, questionando a difundida idéia da rivalidade fraterna. Nota-se que os irmãos mais velhos são tidos como referência e exemplo dos mais novos e desempenham, muitas vezes, o papel de mediadores entre o adolescente e os demais membros da família e o contexto social (Erel, John, \& Margolin, 1998).

De forma geral, as respostas por eles dadas indicam que a comunicação que estabelecem com suas famílias é boa, contrariando a visão, muitas vezes estereotipada, que associa a adolescência a problemas e conflitos familiares.

Como se explicaria então a idéia do adolescente rebelde? Aquele que está freqüentemente descontente com tudo e com todos que o rodeiam?

Talvez a descrição do "Rebelde Sem Causa", como citada na música de Roger Moreira, estaria expressando a busca de diferenciação característica desta fase em famílias de nível soioeconômico médio. Isso é, apesar de o jovem estar vivenciando uma boa comunicação familiar, sentindo-se normalmente compreendido pelos pais, a sua conduta contestatória seria inerente ao processo de construção de sua própria identidade.

Apoiadas nessa hipótese, pensamos que o processo de crescimento do jovem implica em contrariar, às vezes de forma intensa, a autoridade paterna, para, a partir daí, reconhecer-se a si mesmo como um indivíduo único e diferenciado.

Graduar este processo implica em reorganizar o espaço familiar de forma a aumentar a flexibilidade das fronteiras sem que seja comprometida a autoridade dos pais. Por mais que a demanda da fase adolescente, muitas vezes, leve a perder a referência daquilo que, necessariamente, é papel e função familiar, a família deve manter a capacidade de proporcionar um ambiente de segurança, equilíbrio e limites a seus filhos.

\section{REFERÊNCIAS BIBLIOGRÁFICAS}

Aberastury, A, \& Knobel, M. (1990). Adolescência normal. Porto Alegre : Artes Médicas.

Bank, S.P., \& Kahn, M. D. (1997). The sibling bond_(2 ed.). New York, USA : Basic Books.

Blos, P. (1996). Adolescência. Porto Alegre : Martins Fontes.

Carmona, J. (2000). Linha cruzada: a comunicação entre pais e filhos sobre sexualidade. Dissertação de Mestrado, PUCRS.

Carter, B., \& Mc Goldrick, M. (1995). As mudanças no ciclo de vida familiar : Uma estruturação para terapia familiar. Porto Alegre : Artes Médicas.

Cerveny, C. M. O., \& Berthoud, C. M. E. (1997). Família e ciclo vital: Nossa realidade em pesquisa. São Paulo : Casa do Psicólogo.

Cicirelli, V. G. (1995). Sibling relationship across the life span. New York, USA : Plenum Press.

Data Folha (1998, 20 set.). Família. Folha de São Paulo. Especial A1.

Erel, O, John, R. S., \& Margolin, G. (1998). Oberved sibling interaction : Links with the marital and the mother-child relationship. Development Psychology, 34 (2), 288-298.

Falcke, D. (1998). Mães e madrastas : Mitos sociais e auto-conceito. Dissertação de Mestrado, PUCRS.

Grzybowsky, L. S. (2000). Satisfação vital em mulheres separadas/divorciadas. Dissertação de Mestrado, PUCRS.

Horta, R.L. (1998). Paternidade, esquizofrenia e gênero: Um estudo de base fenomenológica. Dissertação de Mestrado, PUCRS.

Osório, L. C. (1992). Adolescente Hoje. Porto Alegre : Artes Médicas.

Perez, A F. (1998). Padrões de relacionamento familiar: O filho primogênito. Dissertação de Mestrado, PUCRS.

Pick, S., \& Palos, P. A. (1995). Impact of the family on the sex lives of adolescents. Adolescent, 30 (119), 667-675.

Richter, H. E. (1990). A Família como paciente. São Paulo : Martins Fontes.

Silveira, L. M. B. O. (2001). Rivalidade, afeição e hostilidade: Diferentes dimensões do relacionamento fraterno. Dissertação de Mestrado, PUCRS.

Wagner, A, Ferreira, V., \& Rodrigues, M. I. M. (1998). Estratégias educativas : Uma perspectiva entre pais e filhos. Psicologia $e$ Argumento, 1 (23), 37-46.

Wagner, A, Halpern, S. C., \& Bornholdt, E. A (1999). Configuração e estrutura familiar: Um estudo comparativo entre famílias originais e reconstituídas. Revista PSICO, 30 (2), 63-73.

Recebido em 03/09/2001

Revisado em 15/04/2002

Aceito em 26/04/2002 
